\title{
Análise dos Fatores Críticos de Implementação do Balanced Scorecard: Soluções para o Setor de Projetos de uma Empresa Petrolífera
}

Noéle Bissoli Perini de Souza noeleperini@gmail.com

Universidade Federal do Espírito Santo (UFES), Vitória, Espírito Santo, Brasil

Marielce de Cássia Ribeiro Tosta

marielce.tosta@ufes.br
Universidade Federal do Espírito Santo (UFES), São Mateus, Espírito Santo, Brasil

\begin{abstract}
RESUMO
Este artigo teve como objetivo analisar as dificuldades enfrentadas pela Equipe de Projetos, de uma empresa petrolífera com atuação no Espírito Santo, quanto à implementação do Balanced Scorecard (BSC) e propor soluções. Para tanto, foi realizado um estudo de caso, utilizando-se, principalmente de entrevistas semiestruturadas e análise documental. Foram constatados vários problemas no BSC existente, tais como visão muito extensa e abrangente, falta de definição de responsáveis por cada indicador de desempenho, definição de muitos objetivos sem que todos tivessem indicadores correspondentes, desequilíbrio entre os indicadores que permeavam as perspectivas do BSC, etc. Em decorrência destes problemas a equipe não conseguia alcançar a nenhum dos objetivos inicialmente propostos. Com o intuito de corrigir e minimizar os problemas anteriores foi elaborada uma nova estratégia dadas à necessidade do setor que possui grande demanda de projetos e o não consegue produzir com a mesma velocidade com que os mesmos chegam. O BSC proposto apresenta sete objetivos estratégicos e doze indicadores com a finalidade de aumentar a produtividade bem como da qualidade dos trabalhos realizados pela equipe. Além disso, espera-se que esta nova versão do BSC possa ser mais efetiva e que permita a sua eficaz implementação e operacionalização.
\end{abstract}

PALAVRAS-CHAVE: Estratégia. Balanced Scorcard (BSC). Perspectivas. Objetivos. Indicadores. 


\section{INTRODUÇÃO}

As estratégias encontram-se presentes em todas as organizações, tanto as mais simples como as maiores e mais complexas, podendo variar em relação ao grau de formalismo com que são formuladas. Uma estratégia pode ser concebida como sequencia temporal de deliberações, ou, alternativamente, como um procedimento que envolve um conjunto de ações voltadas para mover uma organização em direção ao cumprimento de suas metas de curto prazo e seus escopos de longo prazo (JUN et al., 2016).

As estratégias podem ser classificadas das mais diferentes formas: sobrevivência, manutenção, crescimento ou desenvolvimento, as quais podem ajudar a organização a se enquadrar em uma ou mais situações. $O$ executivo poderá escolher determinado tipo de estratégia que seja o mais adequado, tendo em vista a sua capacitação e o objetivo estabelecido. Entretanto, deverá estar ciente de que a escolha poderá nortear o seu desenvolvimento por um período de tempo que poderá ser longo.

Uma vez definida a estratégia, esta deverá ser implementada e gerenciada na organização. Dentre os modelos de gestão utilizados com esta finalidade, ressalta-se o Balanced Scorecard (BSC). Segundo seus criadores, Kaplan e Norton (1992), o modelo foi concebido como ferramenta de gestão, de mensuração balanceada, apoiada em medida financeira e não-financeira, que traduzisse a missão e a estratégia de uma organização em objetivos e medidas tangíveis. Sua proposta original visava superar as limitações da gestão baseada apenas em indicadores financeiros, ou seja, incorporar novos indicadores capazes de comunicar vetores de desempenho futuro, sob a forma de criação de valor mediante investimentos em clientes, fornecedores, empregados, tecnologia e inovação.

Vários trabalhos aplicaram o Balanced Scorecard, em diversas áreas, tais como, segurança escolar (ALOLAH et al., 2014), empresa de corretagem hipotecária (HU et al., 2017), prestadores de serviços de logística terceirizados (RAJESH et al., 2012), gestão de resíduos sólidos urbanos (MENDES et al., 2012), programa de educação ambiental em universidades (GUERRA et al., 2018), bancos comerciais (AL-DWEIKAT e NOUR, 2018), organizações listadas em bolsa de valores (SAAD e DARAGHMA, 2016; CHENG e HUMPHREYS, 2016), instituições federais de ensino superior (CUNHA e KRATZ, 2016) entre outros.

Upadhyay (2012) realizou um estudo de caso desenvolvendo o Balanced Scorecard em uma empresa petrolífera na Índia. A equipe do BSC facilitou a tradução da estratégia organizacional em objetivos operacionais. Ela também desdobrou a estratégia para os funcionários nos formulários e nos quadros que podem ser atingidos e alcançáveis em seu nível. Modelos de BSC e metas de desempenho de funcionários e modelos de metas foram interligados. Esperavase que cada funcionário identificasse seus objetivos e metas individuais, incluindo seus objetivos de aprendizado, de acordo com as quatro perspectivas do BSC.

Apesar da grande relevância, abrangência e difusão do uso do BSC em empresas de diferentes setores alguns trabalhos vem identificando dificuldades em sua implementação. Além disso, parte das empresas que optam pela implantação do modelo fracassa, não chegando a finalizar essa implantação, 
algumas o têm simplesmente abandonado logo após a sua introdução e outras o mantêm sem utilizar plenamente as suas funcionalidades (VIEIRA et al., 2013; MOREIRA et al., 2012; BERTUCCI e HIRSCHEIMER, 2005).

Moreira et al. (2012) levantaram fatores de risco na implantação do BSC, subdivido em dimensões centrais, sendo eles:

- Envolvimento da equipe: falta de comprometimento da alta administração; gestão muito ocupada - problemas de curto prazo; envolvimento de poucas pessoas; encastelamento do BSC no topo; não dividir papéis e responsabilidades; resistência organizacional à mudança;

- Estrutura da organização: organização não está voltada para o aprendizado; empresa não possui estratégia definida; confundir-se com a estratégia; dificuldades no acesso e entendimento das informações; complexidade do ambiente;

- Implantação: falta de discussão da estratégia; estar baseado na estratégia; medidas mal projetadas; utilização no nível organizacional errado; desenvolvimento muito demorado, amplitude inadequado do projeto; relações de causa e efeito mal estabelecidas;

- Processos e objetivos: problemas na circulação das informações, falta de suporte de um sistema de informação; BSC como projeto de uma única área; falta de treinamento; BSC para fins de remuneração, falta de articulação do Balanced Scorecard com as recompensas aos empregados; choque com outras ferramentas administrativas;falta de alinhamento com sistemas existentes; diferenças na definição das medidas; dificuldade em monitorar as medidas não financeiras; estabelecimento de objetivos de curto e longo prazo; e

- Influências externas: fusões e aquisições; interferência sindical; contratação de consultores inexperientes.

Mercer e Wildauer (2015) também analisaram os Fatores Críticos de Sucesso (FCS) na implementação de projetos de Balanced Scorecard e compilaram 29 fatores divididos em 4 etapas cronológicas da metodologia: 1a antes de implantar o BSC; 2a ao desenhar o BSC; 3a ao implantar o BSC; e por fim a 4a ao sustentar o BSC. Os autores ressaltaram entretanto que sete FCS estão em constante interação em todas as fases de implementação do Balanced Scorecard, sendo eles: omissão da alta administração durante o processo de implementação; imediatez do processo; adaptação do programa a organização; precisão na definição de métricas; envolvimento dos colaboradores; comunicação da estratégia e resistências ao Balanced Scorecard.

Os próprios autores do modelo Kaplan e Norton (1997) relatam que nem todas as experiências de implantação foram bem sucedidas. Segundo eles, as dificuldades decorrem de problemas no projeto e de deficiências no processo organizacional. O sucesso da ferramenta estaria relacionado com: a integração entre as quatro perspectivas; o balanceamento entre os graus de importância das perspectivas do BSC; e que o método seja compreendido pela organização como um sistema de gestão estratégica e não somente de gestão financeira. 
Dada à relevância e utilidades do BSC foi elaborado em fevereiro de 2011 um Scorecard e um mapa estratégico para o setor de projetos de uma empresa petrolífera que atua no Espírito Santo que desencadeou em 26 principais objetivos estratégicos ao longo das quatro perspectivas e 12 indicadores. No entanto, os indicadores entraram em desuso sendo que alguns nem chegaram a ser mensurados.

Sendo assim, o objetivo deste artigo foi verificar os fatores que levaram a implementação desta metodologia a falhar e apresentar soluções com o intuito de extrair o máximo do potencial do BSC. Para isto tornou-se necessário apresentar as atribuições da Equipe de Projetos e a estratégia atualmente adotada pelo setor, ou seja, seu Mapa Estratégico e o BSC; descrever a estratégia utilizada, bem como apresentar os principais problemas de sua operacionalização e por fim adaptar e ajustar o BSC e o Mapa Estratégico a uma nova estratégia.

Este artigo está organizado em seis seções, iniciando-se com a presente introdução. Na segunda seção é apresentado os principais conceitos sobre Balanced Scorecard. A terceira seção disserta sobre a metodologia. A quarta seção apresenta o diagnóstico e análise do BSC utilizado pelo setor de projetos seguido da quinta seção com o BSC desenvolvido para o setor de projetos. Por fim, tem-se a sexta seção com as principais conclusões.

\section{BALANCED SCOREDCARD - BSC}

O BSC é um sistema de medição e gerenciamento que ajuda as organizações a traduzir sua visão e estratégia em ação e fornece uma visão geral compreensível para os gerentes do desempenho da organização. Ao fornecer feedback sobre ambos, os processos de negócios internos e os resultados externos desses processos, bem como desempenhos estratégicos podem ser continuamente melhorados. O mesmo não se concentra apenas nos resultados financeiros, mas também nas questões humanas que geram esses resultados, a fim de garantir um melhor desempenho a longo prazo. Assim, destina-se a fazer com que os gerentes se concentrem nas principais métricas de desempenho em um negócio que gera sucesso (RAJESH et al., 2012).

O BSC reúne indicadores de desempenho em quatro perspectivas que estão ligadas numa relação de causa e efeito e que não podem ser vistas de forma independente: "Perspectivas Financeiras", "Perspectiva do Cliente", "Perspectiva do Processo Interno" e "Perspectiva de Aprendizagem e Crescimento". Através dessas perspectivas, o modelo pode ser visto como uma estratégia baseada em uma coleção particular de indicadores críticos que medem o desempenho gerencial na implementação da estratégia de negócios (HU et al., 2017).

A "Perspectiva Financeira" norteará as outras perspectivas, visto que os objetivos financeiros são os objetivos finais de qualquer organização. No início do desenvolvimento do BSC a empresa deverá definir qual a estratégia financeira e os objetivos financeiros da empresa. Devido às possíveis mudanças do mercado e da própria empresa a estratégia e os objetivos devem sempre ser reavaliados (KAPLAN e NORTON, 1997).

A "perspectiva do cliente" trata da identificação dos clientes, suas necessidades e segmentos de mercado, a fim de alinhar as principais medidas de sucesso: satisfação, participação de mercado, fidelização/retenção e captura de 
clientes e rentabilidade. Os resultados de tal abordagem afetam toda a cadeia de valor de uma organização, incluindo suas atividades operacionais, logística, desenvolvimento de produtos e serviços, distribuição e marketing (MENDES et al., 2012).

A "perspectiva de processos internos", por sua vez, representa o conjunto de atividades e ações desenvolvidas. Este monitora e analisa a dimensão operacional da organização e a adequação dos processos internos para alcançar a satisfação do cliente e a otimização financeira. A última perspectiva, da aprendizagem e crescimento, dá suporte às outras três e inclui um conjunto de valores intangíveis, em particular o capital humano, sistemas de informação e gestão e procedimentos organizacionais (KAPLAN e NORTON, 1992).

Para Kaplan e Norton (1997, p. 155) "estratégia é um conjunto de hipóteses sobre causas e efeitos". As relações de causa-efeito são reveladas pela construção de um mapa estratégico, que permite uma descrição da estratégia, o alinhamento de objetivos, metas, ações e indicadores de desempenho selecionados que complementam a informação financeira tradicional. É através dele que se pode perceber o processo de transformação de ativos intangíveis em resultados tangíveis para os clientes, e, por conseguinte, em resultados financeiros. Ou seja, a criação de valor na empresa é indireta, isto é, o investimento em ativos intangíveis, tais como treinamento e conhecimento causam melhoras financeiras por meio das relações de causa e efeito (MENDES et al, 2012; KAPLAN e NORTON, 2000).

Segundo Guerra et al. (2018) os componentes BSC estão associados da seguinte forma:

- Mapa Estratégico: interpretação da estratégia em metas quantificáveis, estabelecendo relações de causa-efeito entre os componentes;

- Os indicadores medem o grau de realização dos objetivos propostos e influenciam o comportamento das pessoas na prossecução da meta;

- As metas e iniciativas proporcionam a rapidez e a prioridade do processo de implementação na busca de alcançar um objetivo; e

- As iniciativas estratégicas especificam como atingir as metas estabelecidas e eliminar ou neutralizar as causas identificadas. Representam um projeto, programa ou estratégia e deve ser interpretado em ações operacionais e orçamentos. Elas devem representar ações ou rotinas operacionais (reuniões, relatórios, etc.). Pode estar relacionada a mais de um objetivo estratégico.

\section{METODOLOGIA}

Esta pesquisa, quanto à abordagem do problema, é do tipo qualitativa, pois o objetivo foi identificar e descrever situações particulares de um sistema complexo, que é o processo de implantação e gestão do BSC, sem enumerar nem medir o evento com instrumentos estatísticos. Dessa forma, buscou identificar e avaliar os problemas enfrentados pela equipe de projetos da empresa estudada no que tange a operacionalização do BSC desenvolvido pela mesma. Assim, a pesquisa teve cunho explanatório por tentar explicar o sucesso e o insucesso, à luz do referencial teórico pesquisado, dos indicadores de desempenho desenvolvidos pela equipe de projetos. Em relação à estratégia adotada, 
apresenta-se como um estudo de caso, aplicado em um setor de projetos que desenvolveu um BSC em uma grande empresa petrolífera com atuação no estado do Espírito Santo.

Para a obtenção dos dados foram utilizados: a pesquisa documental, a entrevista semi-estruturada e a pesquisa bibliográfica. Assim, através de pesquisas em arquivos eletrônicos do setor de projetos, levantou-se a estratégia atual do setor, bem como o seu Scorecard e o seu mapa estratégico. A partir do levantamento inicial da estratégia utilizada no BSC atual da equipe de projetos foram constatados problemas na operacionalização do seu BSC. Pode-se então elaborar um roteiro que foi utilizado em uma entrevista semi-estruturada com o coordenador da equipe. A entrevista permitiu compreensão dos principais problemas enfrentados pela equipe no que tange a operacionalização dos indicadores de desempenho desenvolvidos a partir da metodologia BSC.

A pesquisa bibliográfica permitiu a investigação de obras literárias em geral, não se limitando a autores clássicos, sendo estendida às teses e dissertações de mestrado e doutorado, bem como às revistas técnicas e científicas, artigos de jornais e outros periódicos que deram base teórica para adaptar e ajustar o BSC e o Mapa Estratégico a uma nova estratégia. Possibilitou, ainda, o acesso a outras pesquisas que abordaram o tema evidenciando os fatores críticos e obstáculos à implantação do BSC, erros nos quais geralmente as empresas incorrem quando da implantação. Por se tratar de uma pesquisa qualitativa, que ocorreu nos meses de fevereiro a junho de 2012, a análise dos dados coletados foi feita a partir das proposições do referencial teórico pesquisado. Buscou-se entender os problemas encontrados com o BSC existente e após terem sido feitas todas as considerações foi proposto um novo BSC.

\section{DIAGNÓSTICO E ANÁLISE DO BSC DO SETOR DE PROJETOS}

O objetivo desta seção é apresentar as principais características do setor de projetos, bem como descrever a estratégia atualmente adotada pelo setor. Assim sendo, primeiramente serão feitas algumas considerações gerais e em seguida apresentada a visão e a missão da equipe, com o intuito de ilustrar a estratégia atual. Posteriormente, o Scorecard elaborado pela equipe de projetos será apresentado descrevendo os objetivos estratégicos criados para cada perspectiva e os seus respectivos indicadores. Por último, o mapa estratégico elaborado pelo setor.

Presente em 28 países, a empresa petrolífera, na qual a equipe de projetos pesquisada está inserida, atua nos seguintes setores: exploração e produção, refino, comercialização e transporte de óleo e gás natural, petroquímica, distribuição de derivados, energia elétrica, biocombustíveis e outras fontes renováveis de energia. A equipe de projetos faz parte de uma gerência da empresa que tem como razão de ser:

Planejar, elaborar e executar estudos e projetos de construção, montagem de instalações, equipamentos, automação industrial e engenharia de processamento de forma a contribuir para a realização das metas da organização, respeitando o cumprimento dos custos e prazos, a qualidade, a segurança e o meio ambiente. 
No momento da realização desta pesquisa a gerência possuía uma carteira de projetos bastante extensa que ultrapassava 100 projetos. Vale destacar que na carteira de projetos havia demandas que foram abertas em 2008 e somente em 2012 o projeto começou a ser elaborado.

A gerência é subdividida em cinco equipes, são elas: Equipe de Gestão Integrada (GI); Equipe de Planejamento e Materiais (P\&M); Equipe de Projetos (PROJ); Equipe de Processamento (PROC); e Equipe de Construção e Montagem (C\&M), cujas relações são apresentadas na Figura 1.

Figura 1 - Estrutura organizacional

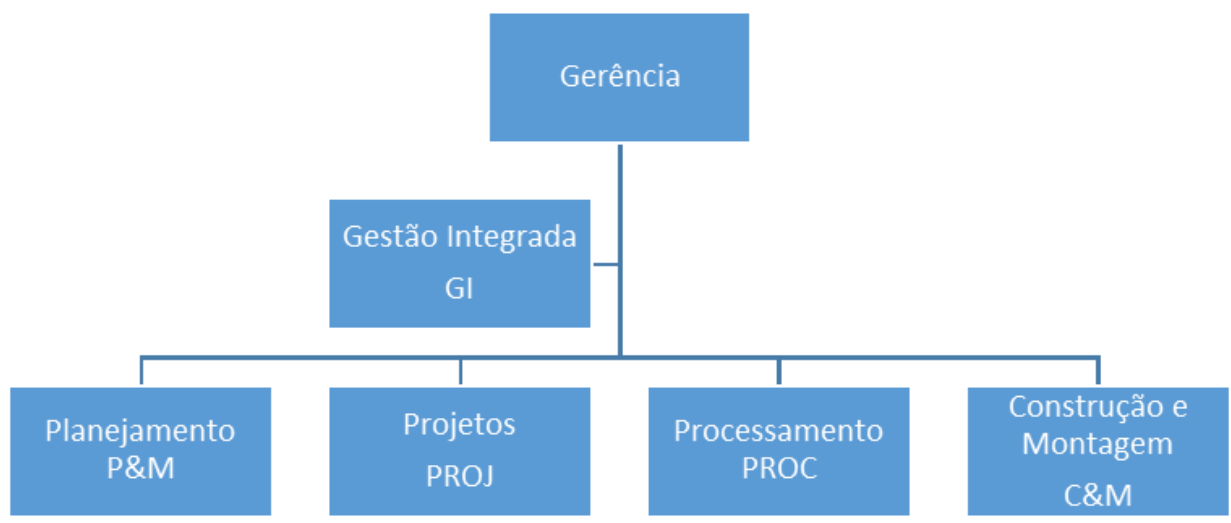

Fonte: Equipe de projetos

A equipe de projetos é formada por um coordenador, um planejador, três engenheiros civis e três mecânicos, dois engenheiros elétrico, três técnicos de instrumentação e um técnico de documentação. O coordenador, um técnico de instrumentação e um engenheiro elétrico são empregados da própria empresa, sendo os demais colaboradores contratados por outras duas empresas. Ao decorrer do texto serão denominados de empregados contratados, pois estes trabalham dentro do setor estudado, em regime administrativo (8 horas por dia), porém são remunerados por suas respectivas empresas.

Assim, a equipe de projetos estudada tem como atribuições:

a) elaborar e fiscalizar projetos conceituais, básicos, e executivos dos empreendimentos, nas disciplinas civil, elétrica, mecânica e instrumentação;

b) elaboração de estudos técnicos nas disciplinas civil, elétrica, mecânica, e instrumentação;

c) revisar os documentos de projeto conforme modificações informadas pela construção e montagem;

d) emitir os pareceres técnicos de equipamentos e materiais;

e) assessorar as gerências de operação em melhorias do processo de produção e processamento de óleo e gás;

f) prover suporte técnico durante a aquisição de materiais; 
g) prover suporte técnico nas fases de construção e montagem;

h) atuar na atualização tecnológica de softwares de elaboração de projetos, softwares auxiliares e estações de trabalho;

i) coordenar testes de novas tecnologias de engenharia de instalações de superfície em parcerias com outros órgãos da companhia;

j) participar da elaboração dos padrões e procedimentos operacionais;

k) coordenar o recebimento e o cadastramento da documentação técnica dos empreendimentos;

I) representar a gerência no grupo de trabalho de automação de projetos.

O setor de projetos desenvolveu no primeiro semestre de 2011, o Balanced Scorecard (BSC). Esperava-se com isso, que se obtivessem informações de desempenho, a partir de uma estratégia definida. Desta forma foi definida a missão e visão para o setor, respectivamente, como:

"Desenvolver estudos, consultoria técnica, elaborar e fiscalizar a execução de projetos conceituais, básicos e executivos de engenharia, para atender as necessidades das unidades operacionais, contribuindo para o aumento da disponibilidade e da capacidade de processamento, primando sempre pelo cumprimento dos prazos, otimização técnico-econômica e a segurança das instalações, pessoas e meio ambiente."

"Ser reconhecida pelos clientes e pela organização como modelo de gestão interna, níveis de excelência técnica, produtividade e qualidade. Promovendo maior interação entre os envolvidos no processo produtivo."

Assim sendo, o setor de projetos elaborou o mapa (Figura 2) com a finalidade de representar as relações de causa e efeito entre os componentes da estratégia.

Por meio da entrevista com o coordenador da área de projetos, vários problemas em operacionalizar os indicadores foram diagnosticados. Dos 12 indicadores de desempenho descritos no Scorecard do setor de projetos três "ensaiaram" uma medição no ano de 2011: o Índice de Participação nos Diálogos de Segurança, Meio Ambiente e Saúde (IPDSMS) acompanhado nos meses de maio, junho e julho; o Índice de Realização de Check List dos projetos (IRCL) medido em maio; e o Índice de Cumprimento de Custo (ICC) nos meses de maio e junho. E de todas as planilhas criadas somente o IPDSMS e IRCL foram preenchidas.

Feito este diagnóstico inicial foi realizado uma análise de todo o documento onde se constatou que a missão, por ter caráter mais abrangente, foi considerada adequada. Já a visão, estava muito extensa e abrangente, ou seja, não focalizava uma questão estratégica que pudesse dar base ao BSC. Ao contrário, considerava alcançar diversos objetivos, tais como, eficiência, qualidade e produtividade. 
Figura 2 - Mapa estratégico

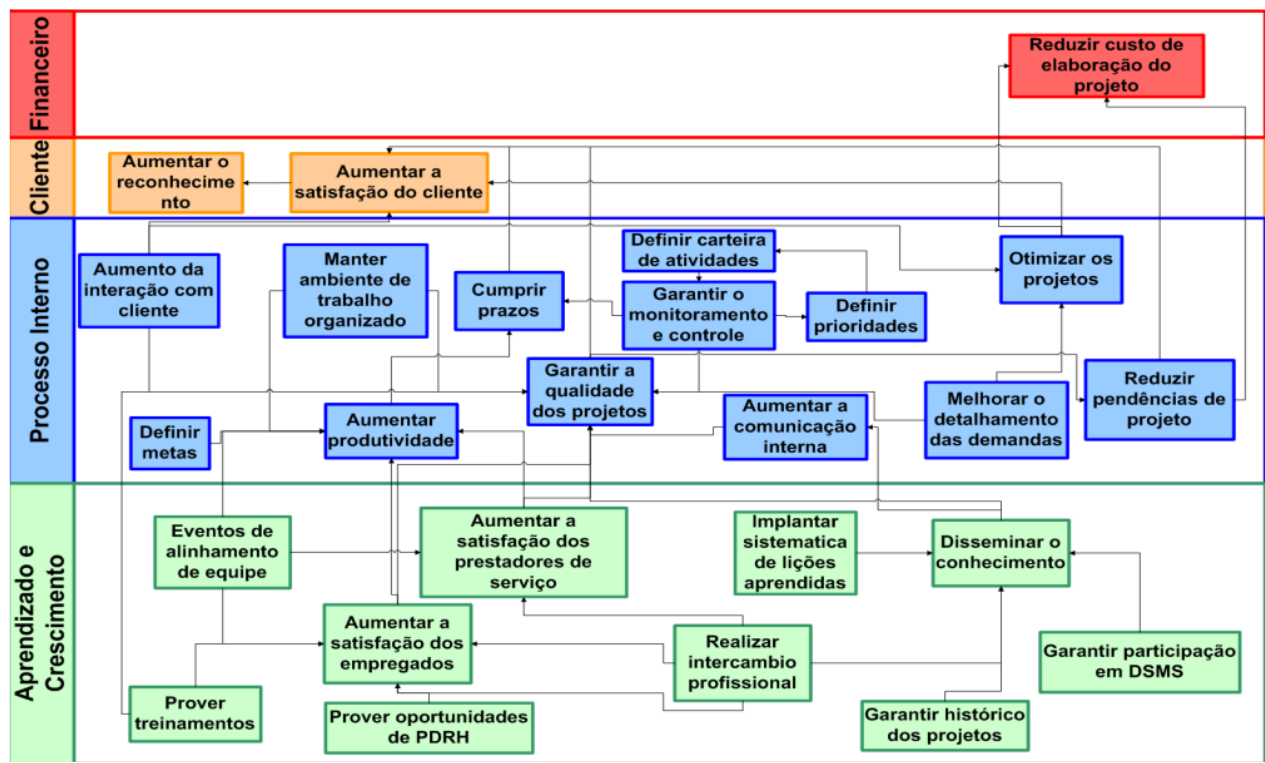

Fonte: Equipe de projetos

Outra questão está relacionada a não definição de responsáveis por cada indicador de desempenho e suas respectivas metas, além da não existência de parâmetros a serem alcançados, desta forma não existia controle. Pode-se, também, verificar que os objetivos foram definidos associando-os aos indicadores, em vez de focar primeiramente na definição dos objetivos estratégicos e suas relações de causa e efeito, como aconselha a metodologia do BSC. Ao analisar os objetivos estratégicos da equipe pode-se perceber que dos 26 objetivos propostos 10 não exibiram indicador (Tabela 1). Portanto, mesmo que fossem relevantes não teria possibilidade de alcançá-los uma vez que estes não poderiam ser mensurados.

Tabela 1 - Quantidade de objetivos com e sem indicador

\begin{tabular}{cccc} 
Perspectiva & $\begin{array}{c}\text { Objetivos com } \\
\text { indicador }\end{array}$ & $\begin{array}{c}\text { Objetivos sem } \\
\text { indicador }\end{array}$ & $\begin{array}{c}\text { Total de } \\
\text { objetivos }\end{array}$ \\
$\begin{array}{c}\text { Aprendizado e crescimento } \\
\text { Processo interno }\end{array}$ & 6 & 4 & 10 \\
Cliente & 1 & 5 & 13 \\
Financeiro & 1 & 1 & 2 \\
Total & 16 & - & 1 \\
\hline
\end{tabular}

Fonte: Resultados da pesquisa.

De acordo com a Tabela 2 pode-se verificar que a distribuição da quantidade de indicadores nas quatro perspectivas do BSC $(8,3 \%$ dos indicadores para a perspectiva financeira, $0 \%$ para a perspectiva do cliente, $50 \%$ para a perspectiva dos processos internos e $41,7 \%$ para a perspectiva do aprendizado e crescimento) 
não apresentou equilíbrio entre os indicadores que o permeiam, e, mais agravante, não apresentou nenhum indicador para a perspectiva do cliente, o que impossibilitou a análise de causa e efeito. Ressalta-se ainda que $8,3 \%$ dos indicadores correspondem às perspectivas externas (financeira e do cliente) e 91,7\% estão nas duas perspectivas internas (processos internos e aprendizado e crescimento). Este último pode ser explicado devido à maior facilidade na obtenção de informações para a composição dos indicadores.

Tabela 2 - Quantidade de indicadores utilizados e não utilizados

\begin{tabular}{cccc} 
Perspectiva & $\begin{array}{c}\text { Indicador não } \\
\text { utilizado }\end{array}$ & $\begin{array}{c}\text { Indicador } \\
\text { utilizado }\end{array}$ & $\begin{array}{c}\text { Total de } \\
\text { indicadores } \\
\text { elaborados }\end{array}$ \\
$\begin{array}{c}\text { Aprendizado e crescimento } \\
\text { Processo interno }\end{array}$ & 1 & 5 & 6 \\
Cliente & 7 & 6 & 13 \\
Financeiro & 1 & - & 1 \\
Total & 1 & 1 & 2 \\
\hline
\end{tabular}

Fonte: Resultados da pesquisa.

Quanto às metas que foram definidas ressalta-se que a relativa ao índice de cumprimento de prazo de projeto pode ser considerada como não realizável, pois possíveis atrasos na elaboração do projeto não são considerados. As demais metas dos outros 11 indicadores poderiam ter sido realizadas. Por se tratar de um setor de projetos, ou seja, caracterizado por ser um prestador de serviços, as únicas maneiras de aumentar os lucros são a redução dos custos e a melhoria da produtividade. Como na gerência pesquisada há grande demanda por projetos, pretendeu-se elaborar um novo BSC com o intuito de aumentar a produtividade da equipe para atender com maior rapidez aos clientes.

\section{BSC PROPOSTO}

Feita todas as considerações sobre BSC atual, bem como todos os problemas referentes à elaboração e implementação deste, pode-se propor alterações cabíveis. Assim sendo, o primeiro passo foi definir uma nova estratégia, sendo esta, a liderança em custos, associada à estratégia de desenvolvimento. A estratégia de custo implica sistema de controles rígidos, busca de economias de escala e dedicação à curva de aprendizagem, inovações tecnológicas e disciplina e atenção aos detalhes. A estratégia de desenvolvimento por sua vez, está associada ao ser humano. A ênfase dessa estratégia localiza-se no desenvolvimento do capital intelectual e recursos tecnológicos da organização. Decorre daí na inovação nos processos e nos produtos.

Para corroborar a estratégia uma nova visão foi proposta, mais clara e curta. De tal modo que ao alcançar os resultados pretendidos a mesma pode ser revisada a fim de que outro problema possa ser resolvido, e assim 
sucessivamente, visto que o BSC tem caráter dinâmico. Desta forma a missão e visão para o setor são respectivamente:

"Desenvolver estudos, consultoria técnica, elaborar e fiscalizar a execução de projetos conceituais, básicos e executivos de engenharia, para atender as necessidades das unidades operacionais, contribuindo para o aumento da disponibilidade e da capacidade de processamento, primando sempre pelo cumprimento dos prazos, otimização técnico-econômica e a segurança das instalações, pessoas e meio ambiente."

"Alcançar aumento da produtividade sem comprometer a qualidade técnica dos projetos."

Uma vez que o setor de projetos possui grande carteira de trabalhos e por vezes fica com projetos atrasados e pendentes, além de que os colaboradores do setor declararam que viam o BSC como mais uma burocracia, todavia o coordenador necessita dos indicadores para acompanhar e motivar a equipe, foi desenvolvido um modelo mais dinâmico e com indicadores mais específicos e práticos. A proposta do BSC está apresentada nos Quadros 1, 2, 3 e 4, e possui sete objetivos e doze indicadores. As relações de causa e efeito podem ser verificadas no Mapa Estratégico (Figura 3).

Quadro 1 - Scorecard proposto - perspectiva aprendizado e crescimento

\begin{tabular}{|c|c|c|c|c|}
\hline $\begin{array}{l}\text { Objetivos } \\
\text { estratégicos }\end{array}$ & Indicadores & Sigla & Periodicidade & Fórmula /Evidência \\
\hline $\begin{array}{l}\text { Motivar os } \\
\text { funcionários }\end{array}$ & $\begin{array}{l}\text { Qtd de reuniões de } \\
\text { equipe de projetos }\end{array}$ & QREP & Mensal & $\begin{array}{l}\text { Qtd de reuniões de equipe de } \\
\text { projetos realizadas }\end{array}$ \\
\hline \multirow{2}{*}{$\begin{array}{c}\text { Treinar } \\
\text { funcionários }\end{array}$} & $\begin{array}{c}\text { Índice de participação } \\
\text { nos DSMS }\end{array}$ & IPDSMS & Mensal & $\begin{array}{c}\text { IPDSMS = Frequência de } \\
\text { participação / Nº de DSMS }\end{array}$ \\
\hline & $\begin{array}{c}\text { Índice de disseminação } \\
\text { do conhecimento }\end{array}$ & IDC & Bimestral & $\begin{array}{l}\mathrm{IDC}=\text { Qtd de workshops } \\
\text { realizados } \mathrm{p} / \text { disciplinas }\end{array}$ \\
\hline $\begin{array}{c}\text { Fornecer } \\
\text { feedback aos } \\
\text { funcionários }\end{array}$ & $\begin{array}{l}\text { Índice de histórico de } \\
\text { projetos }\end{array}$ & IHP & Por projeto & $\begin{array}{c}\mathrm{IHP}=\left(\mathrm{N}^{\circ} \text { de projetos com }\right. \\
\text { histórico preenchido/ } \mathrm{N}^{\circ} \text { total de } \\
\text { projetos concluídos }) \times 100 \%\end{array}$ \\
\hline $\begin{array}{c}\text { Objetivos } \\
\text { estratégicos }\end{array}$ & Indicadores & Meta & Responsável & Plano de Ação \\
\hline $\begin{array}{l}\text { Motivar os } \\
\text { funcionários }\end{array}$ & $\begin{array}{l}\text { Qtd de reuniões de } \\
\text { equipe de projetos }\end{array}$ & QREP $\geq 1$ & Coordenador & $\begin{array}{l}\text { Apresentar mensalmente os } \\
\text { indicadores de desempenho da } \\
\text { área, bem como fornecer } \\
\text { feedback dos serviços }\end{array}$ \\
\hline \multirow{2}{*}{$\begin{array}{c}\text { Treinar } \\
\text { funcionários }\end{array}$} & $\begin{array}{c}\text { Índice de participação } \\
\text { nos DSMS }\end{array}$ & $\begin{array}{l}\text { IPDSMS } \\
=90 \%\end{array}$ & SEG & \multirow{2}{*}{$\begin{array}{l}\text { Lembrar os colaboradores do } \\
\text { DSMS } 30 \text { min antes do mesmo e } \\
\text { Montar cronograma bimestral } \\
\text { de workshops de cada disciplina }\end{array}$} \\
\hline & $\begin{array}{c}\text { Índice de disseminação } \\
\text { do conhecimento }\end{array}$ & $I D C \geq 1$ & Coordenador & \\
\hline $\begin{array}{c}\text { Fornecer } \\
\text { feedback aos } \\
\text { funcionários }\end{array}$ & $\begin{array}{l}\text { Índice de histórico de } \\
\text { projetos }\end{array}$ & $\begin{array}{l}\mathrm{IHP} \geq \\
60 \%\end{array}$ & Planejador & $\begin{array}{l}\text { Anexar o histórico de projeto } \\
\text { aos documentos do projeto } \\
\text { sempre que este for } \\
\text { encaminhado de um } \\
\text { colaborador a outro }\end{array}$ \\
\hline
\end{tabular}

Fonte: Resultados da pesquisa 
Quadro 2 - Scorecard proposto - perspectiva processo interno

\begin{tabular}{|c|c|c|c|c|}
\hline $\begin{array}{c}\text { Objetivos } \\
\text { estratégicos }\end{array}$ & Indicadores & Sigla & Periodicidade & Fórmula /Evidência \\
\hline \multirow{4}{*}{$\begin{array}{l}\text { Reduzir tempo } \\
\text { de entrega do } \\
\text { projeto }\end{array}$} & $\begin{array}{l}\text { Percentual de clientes atendidos } \\
\text { com uma única visita de serviço }\end{array}$ & PCAUV & Semestral & $\begin{array}{c}\text { PCAUV = ( } \mathrm{N}^{\circ} \text { de projetos finalizados } \\
\text { com uma única apresentação ao } \\
\text { cliente } / \mathrm{N}^{\circ} \text { total de projetos } \\
\text { concluídos })\end{array}$ \\
\hline & Tempo de ciclo & TC & Por projeto & $\begin{array}{c}\text { TC = (Data de entrada da demanda na } \\
\text { carteira de projetos - Data de } \\
\text { finalização da demanda na carteira } \\
\text { de projetos) }\end{array}$ \\
\hline & $\begin{array}{l}\text { Índice de cumprimento de prazo } \\
\text { de projeto }\end{array}$ & ICPP & Por projeto & $\begin{array}{l}\text { ICPP = Duração realizada/Duração } \\
\text { prevista }\end{array}$ \\
\hline & $\begin{array}{l}\text { Número de vezes que o projeto } \\
\text { precisou ser modificado }\end{array}$ & NVPM & Por projeto & $\begin{array}{l}\text { Qtd de vezes que o projeto precisou } \\
\text { ser modificado }\end{array}$ \\
\hline \multirow{2}{*}{$\begin{array}{l}\text { Garantir a } \\
\text { qualidade dos } \\
\text { projetos }\end{array}$} & $\begin{array}{l}\text { Qtd de não conformidade de } \\
\text { projetos }\end{array}$ & QNCPR & Mensal & Qtd de NC's registradas \\
\hline & $\begin{array}{l}\text { Índice realização de checklist dos } \\
\text { projetos }\end{array}$ & IRCL & Por projeto & $\begin{array}{c}\mathrm{IRCL}=\text { (Qtd de checklist } \\
\text { preenchidos/Qtd de projetos }) \times 100\end{array}$ \\
\hline $\begin{array}{c}\text { Objetivos } \\
\text { estratégicos }\end{array}$ & Sigla & Meta & Responsável & Plano de Ação \\
\hline \multirow{4}{*}{$\begin{array}{l}\text { Reduzir tempo } \\
\text { de entrega do } \\
\text { projeto }\end{array}$} & PCAUV & $\begin{array}{l}\text { PCAUV } \geq \\
50 \%\end{array}$ & Planejador & \multirow{4}{*}{$\begin{array}{l}\text { Apresentar o resultado destes } \\
\text { indicadores nas reuniões de equipe }\end{array}$} \\
\hline & TC & $\mathrm{TC} \leq 1$ ano & Planejador & \\
\hline & ICPP & ICPP $\leq 1,1$ & Planejador & \\
\hline & NVPM & NVPM $\leq 2$ & Planejador & \\
\hline \multirow{2}{*}{$\begin{array}{l}\text { Garantir a } \\
\text { qualidade dos } \\
\text { projetos }\end{array}$} & QNCPR & $\mathrm{QNCPR} \leq 2$ & Gestão & \multirow{2}{*}{$\begin{array}{l}\text { Apresentar o resultado destes } \\
\text { indicadores nas reuniões de equipe }\end{array}$} \\
\hline & IRCL & $\mathrm{IRCL} \geq 90 \%$ & Planejador & \\
\hline
\end{tabular}

Fonte: Resultados da pesquisa

Quadro 3-Scorecard proposto - perspectiva cliente

\begin{tabular}{|c|c|c|c|c|}
\hline $\begin{array}{c}\text { Objetivos } \\
\text { estratégicos }\end{array}$ & Indicadores & Sigla & Periodicidade & Fórmula /Evidência \\
\hline $\begin{array}{c}\text { Aumentar } \\
\text { satisfação } \\
\text { do cliente }\end{array}$ & $\begin{array}{c}\text { Índice de } \\
\text { satisfação } \\
\text { dos clientes }\end{array}$ & ISC & Trimestral & $\begin{array}{c}\text { ISC }= \\
{\left[\left(\mathrm{PCAUV}_{\mathrm{i}} / \mathrm{PCAUV}_{\mathrm{m}}\right)+\left(\mathrm{TC}_{\mathrm{i}} / \mathrm{TC}_{\mathrm{m}}\right)+\left(\mathrm{ICPP} / / \mathrm{ICPP}_{\mathrm{m}}\right)+\left(\mathrm{NVPM}_{\mathrm{i}} / \mathrm{NVPM}_{\mathrm{m}}\right)\right]} \\
\mathrm{x} 100\end{array}$ \\
\hline $\begin{array}{c}\text { Objetivos } \\
\text { estratégicos }\end{array}$ & Indicadores & Meta & Responsável & Plano de Ação \\
\hline $\begin{array}{c}\text { Aumentar } \\
\text { satisfação } \\
\text { do cliente }\end{array}$ & $\begin{array}{c}\text { Índice de } \\
\text { satisfação } \\
\text { dos clientes }\end{array}$ & $\begin{array}{c}\mathrm{ISC} \geq \\
3,2\end{array}$ & Planejador & Apresentar o resultado deste indicador nas reuniões de equipe \\
\hline
\end{tabular}

Fonte: Resultados da pesquisa

Quadro 4-Scorecard proposto - perspectiva financeiro

\begin{tabular}{|c|c|c|c|c|}
\hline $\begin{array}{c}\text { Objetivos } \\
\text { estratégicos }\end{array}$ & Indicadores & Sigla & Periodicidade & Fórmula /Evidência \\
\hline $\begin{array}{c}\text { Reduzir o } \\
\text { custo de } \\
\text { elaboração do } \\
\text { projeto }\end{array}$ & $\begin{array}{c}\text { Índice de cumprimento } \\
\text { de custo }\end{array}$ & ICC & Por projeto & ICC = (Custo realizado / Custo \\
planejado)
\end{tabular}

Fonte: Resultados da pesquisa 
Figura 3 - Mapa estratégico proposto

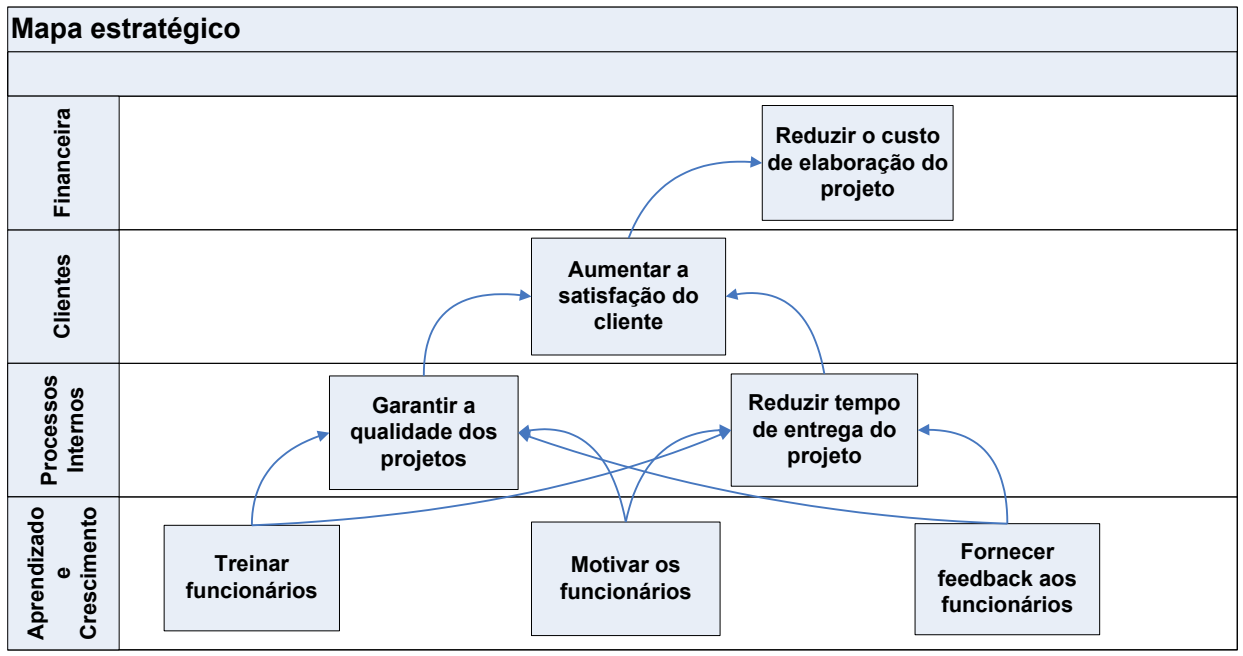

Fonte: Resultados da pesquisa

\section{PERSPECTIVA FINANCEIRA}

Ao analisar o Índice de Cumprimento de Custo (ICC) percebeu-se que o problema não estava no índice, mas na falta de acompanhamento do mesmo. Assim sendo, este deve ser mantido e mensurado através da Equação (1):

$$
I C C=\frac{\text { custo realizado }}{\text { custo planejado }}
$$

No entanto, o responsável por este indicador será o planejador que o atualizará assim que um projeto for finalizado. Propõe-se como aceitável o seguinte intervalo $0,9 \leq \mathrm{ICC} \leq 1,1$, pois não é interessante que os custos ultrapassem ou fiquem muito abaixo dos custos planejados. Custos realizados acima do planejado aumentam os custos do projeto e custos realizados muito abaixo do planejado indicam problemas de orçamentação. Estes valores foram definidos em conjunto com o coordenador da equipe.

Como ressaltado anteriormente, existia no setor problemas quanto ao orçamento. Este era realizado intuitivamente, no momento de sua elaboração a planejadora perguntava a cada colaborador qual era o tempo necessário para o cumprimento da tarefa. Com os tempos em mãos, multiplicava-se este valor pelo valor da hora do profissional previsto em contrato. Com isso chegava-se ao valor estimado do projeto.

Para minimizar este problema foi necessário criar um direcionador de custo. Como o resultado do trabalho da equipe de projetos são documentos de diferentes formatos e tipos, o direcionador proposto é Hora Homem $(\mathrm{HH})$ por tipo de documento. Listaram-se todos os tipos de documento em cada formato e determinou-se um HH/documento padrão. Com este direcionador foi elaborado um modelo de orçamento chamado de Proposta de Trabalho. 
Foi elaborado um sistema no programa Access de acompanhamento de horas por documento. Ao final de cada dia de trabalho o colaborador insere no sistema em quais projetos trabalhou, quais os respectivos tipos de documentos e quantas horas foram despendidos em cada documento especificado. Este sistema gera relatórios de acompanhamento do desempenho da equipe, além de futuramente poder ser revisado o $\mathrm{HH}$ padrão/documento visando adequá-lo ao tempo real que a equipe de projetos utiliza para cada documento.

\section{PERSPECTIVA DOS CLIENTES}

Os clientes da equipe de projetos (PROJ) são outros setores da própria empresa, esses não estão preocupados com o valor que o serviço custa a organização, nem com a imagem e reputação da equipe, pois não existe relação de concorrência com outros fornecedores, sendo a equipe de projetos sua única opção para obter o serviço desejado. No entanto, é de fundamental importância que os projetos sejam desenvolvidos com precisão e em tempo hábil. Quando isto não ocorre atrasa os trabalhos dos demais setores e gera muita insatisfação. Portanto, o objetivo estratégico desta perspectiva deve ser Aumentar a satisfação dos clientes.

Uma vez que a satisfação dos clientes é uma variável muito pessoal, e que a simples pergunta, se o cliente estaria satisfeito, poderia não ser um indicador confiável, e considerando que a satisfação, neste caso, está diretamente associada ao tempo de execução dos projetos, propõe-se o Índice de Satisfação dos Clientes (ISC - Equação 2). Este indicador deve monitorar outros departamentos da própria empresa (clientes da PROJ) e será composto por variáveis relativas aos indicadores correspondentes ao objetivo Reduzir tempo de entrega do projeto da perspectiva do processo interno explicado adiante.

$$
I S C=\frac{P C A U V_{i}}{P C A U V_{m}}+\frac{T C_{i}}{T C_{m}}+\frac{I C P P_{i}}{I C P P_{m}}+\frac{N V P M_{i}}{N V P M_{m}}
$$

Onde:

- PCAUV = percentual de clientes atendidos com uma única visita de serviço;

- TC = tempo de ciclo;

- ICPP = índice de cumprimento de prazo de projeto;

- NVPM = número de vezes que o projeto precisou ser modificado.

$-\mathrm{i}=$ do projeto mensurado;

- $\mathrm{m}=$ da meta

A meta é ter no mínimo $80 \%$ dos clientes satisfeitos. Como este índice tem uma escala que varia de 0 a 4, ele deve ser maior que 3,2. A responsabilidade da manutenção deste indicador será do planejador que é o colaborador que sempre está presente na apresentação de entrega de projeto. Como a elaboração dos projetos demanda tempo a periodicidade de manutenção deste indicador será trimestral. 


\section{PERSPECTIVA DOS PROCESSOS INTERNOS}

O BSC implementado considera 13 objetivos estratégicos para esta perspectiva. Propõem-se reduzir este número para dois, sendo eles: Reduzir tempo de entrega do projeto e Garantir a qualidade dos projetos. Pois a qualidade e o tempo de resposta e entrega são atributos bastante visíveis aos clientes da PROJ. Deste modo, a redução do tempo de resposta e entrega do projeto e a garantia da qualidade dos projetos (perspectiva dos processos internos) provocarão um aumento na satisfação dos clientes (perspectiva do cliente).

O objetivo Cumprir prazos foi retirado, pois entende-se que está incorporado no objetivo proposto Reduzir tempo de entrega do projeto. O objetivo Aumentar a produtividade foi suprimido, pois entende-se que com o alcance do objetivo Reduzir tempo de entrega do projeto, a equipe estará aumentando a produtividade, ou seja, tem-se o mesmo efeito. Os demais objetivos da perspectiva anterior não foram considerados, pois, concluiu-se que não ajudariam no alcance da estratégia atual.

Assim sendo, para o objetivo Garantir a qualidade dos projetos foram definidos dois indicadores: Quantidade de Não Conformidade de Projeto (QNCPR) e o Índice de Realização de Check List (IRCL). Já para o objetivo Reduzir tempo de entrega do projeto, quatro indicadores foram formulados: Percentual de Clientes Atendidos com uma Única Visita de serviço (PCAUV), Tempo de Ciclo (TC), Índice de Cumprimento de Prazo de Projeto (ICPP) e Número de Vezes que o Projeto precisou ser Modificado (NVPM).

Percebeu-se que para operacionalizar o QNCPR faltava definir um processo de registro de não conformidades (NC's) dentro da gerência. Assim, após duas reuniões com os coordenadores das equipes de P\&M, de PROC, de PROJ, de C\&M e de Gl, definiu-se um fluxo de registro e controle de não conformidades apresentados na Figura 4. Este processo pode ser descrito como:

a) Identificar a NC: O Emissor, ao identificar uma não conformidade (NC) emite o registro de não conformidade (RNC).

b) Registrar a NC: O Emissor preenche a Ficha de RNC informando a data, o número que identifica o projeto, o título do projeto, a disciplina a que se refere à NC, quando esta for cabível, a área a qual a NC se refere, bem como a descrição da NC aberta. Neste registro também deve constar o nome do Emissor e do Responsável pela área que receberá a NC. Após registrar a NC, o Emissor a encaminhará a Gestão.

c) Numerar a NC: Ao receber a NC a Gestão deve numerá-la e encaminhá-la ao Responsável pela área a que se refere à NC aberta.

d) Avaliar a NC: O Responsável examinará a NC emitindo parecer se procede ou não. Se proceder, o mesmo deverá dar o tratamento adequado a esta. Se não proceder, o Responsável deverá justificar no campo de observações o que o levou a não considerar a NC.

e) Cadastrar a NC na Planilha de Controle de Registro de Não Conformidade (PCRNC): Após o Responsável ou o Gerente informarem que a NC procede, a Gestão cadastrará a mesma na Planilha de Controle de Registro de Não Conformidade do ano presente. Somente após esta planilha ser alimentada, 
gráficos serão gerados: um gráfico consolidado com a evolução das NC's e um gráfico para cada área estratificando cada disciplina.

f) Tratar a NC: O Responsável deverá tratar a NC que for confirmada por ele próprio ou pelo Gerente.

g) Não cadastrar a NC na PCRNC: A Gestão não cadastrará na PCRNC aquelas que forem rejeitadas, devendo encerrar o processo.

h) Avaliar o Tratamento dado a NC: Estará a cargo do Emissor da NC avaliar o tratamento dado a sua solicitação pelo Responsável como adequado ou não. Se a avaliação for como não adequado, o Emissor deverá justificar sua decisão.

i) Encerrar o Processo: A Gestão estará encarregada de encerrar o processo. Portanto é a Gestão a responsável pelo controle deste indicador, apresentando-o sempre nas reuniões mensais da gerência.

Com o intuito de controlar este índice dentro da PROJ, propõe-se como meta específica para esta equipe a ocorrência de no máximo duas não conformidades de projetos ao mês.

Figura 4 - Fluxograma de registro e controle de não conformidades

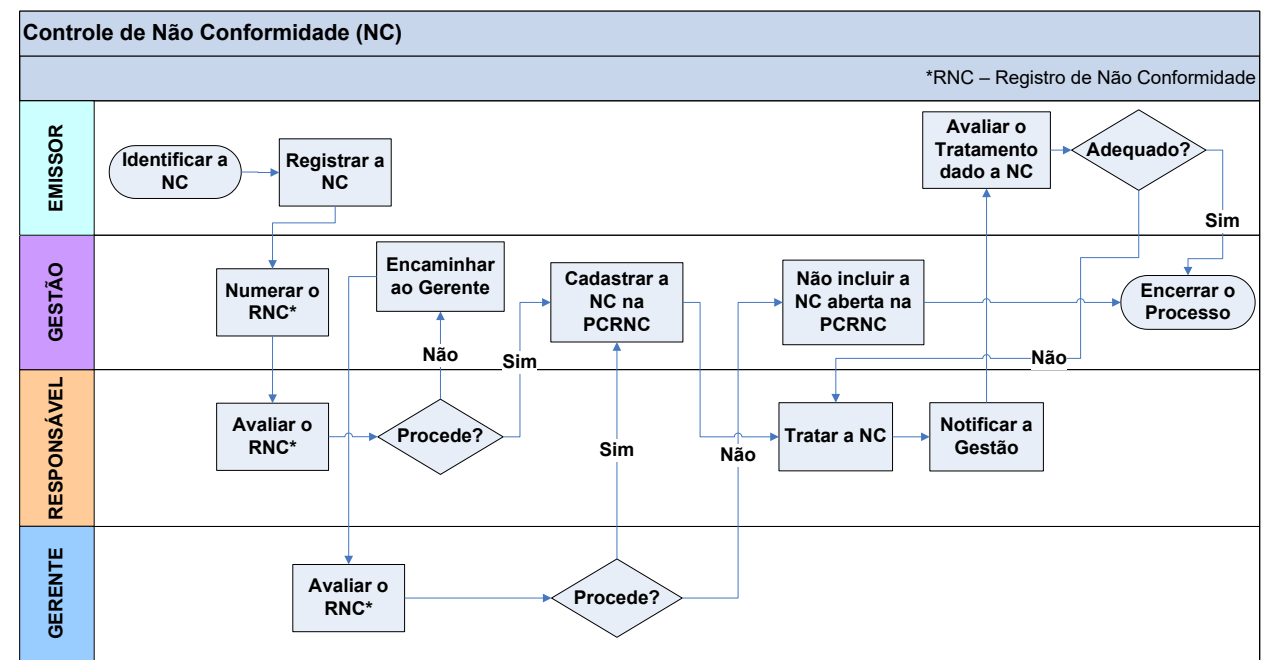

Fonte: Resultados da pesquisa

No que tange ao Índice de Realização de Check List (IRCL), percebeu-se que o problema não estava no indicador, mas na sua operacionalização, já que a sua realização estava em desuso dentro da equipe pois o mesmo era grande e redundante. Assim, todos os seis check list foram revisados com o intuito de simplificá-los, mas com cuidado para que itens importantes não fossem retirados, e, fazer com que a prática do preenchimento do mesmo não venha a ser abandonada novamente. Assim, o IRCL será mantido e mensurado através da Equação (3):

$$
I R C L=\frac{(Q t d . C L P)}{(Q t d . P r o j)} \times 100
$$


Onde: Qtd.CLP representa a quantidade de check list preenchidos e Qtd.Proj a quantidade de projetos. Pretende-se atingir no mínimo $90 \%$ de check list preenchidos em no máximo dois meses. Propõe-se como responsável por este indicador, o planejador da equipe que se comprometerá a atualizá-lo sempre que um projeto for finalizado.

O Percentual de Clientes Atendidos com uma Única Visita de serviço (PCAUV) será mensurado através da Equação (4):

$$
P C A U V=\frac{\left(n^{\circ} \text { proj.FUAC }\right)}{\left(n^{\circ} \text { proj.concl }\right)}
$$

Onde: $n$ o proj.FUAC representa o número de projetos finalizados com uma única apresentação ao cliente e no proj.concl o número total de projetos concluídos.

Este indicador tem o intuito de monitorar a redução do tempo de entrega do projeto. Sua meta é entregar com uma única visita pelo menos metade dos projetos elaborados em seis meses, devido o tempo de elaboração de alguns projetos serem mais extensos. O responsável definido para este indicador é o planejador, já que ele é o profissional que acompanha a vida de cada projeto e é o único que sempre se encontra na apresentação de entrega de projeto, portanto com facilidade para alimentá-lo.

O Tempo de Ciclo (TC) tem a intenção de controlar o tempo de permanência do projeto na carteira e será mensurado através da Equação (5):

$$
T C=(\text { data inicial })-(\text { data final })
$$

Onde: a data inicial é a de entrada da demanda na carteira de projetos e a data final é a de finalização da demanda na carteira de projetos. Definiu-se como meta o atendimento da demanda em no máximo 1 ano, meta essa a ser atingida em 2 ou 3 anos. Pois a gerência possui uma carteira bastante sobrecarregada de projetos, recebendo projetos dos mais diversos tamanhos e complexidades, o que faz com que projetos considerados relativamente simples fiquem mais tempo do que deveria na carteira. Pelos mesmos motivos apresentados no PCAUV, também é o planejador o colaborador responsável pelo TC.

O Índice de Cumprimento de Prazo de Projeto (ICPP) será mensurado por meio da Equação (6):

$$
I C P P=\frac{\text { duração realizada }}{\text { duração prevista }}
$$

Este pretende acompanhar, sob responsabilidade do planejador, a duração realizada e compará-la com a prevista, buscando sempre ser menor do que 1,1, ou seja, evitar atrasos na elaboração dos projetos maior que $10 \%$. Este valor foi definido visto que no BSC existente não se considerava atrasos na elaboração dos projetos, o valor da meta era igual 1. 
Quanto menor for o Número de Vezes que o Projeto precisou ser Modificado (NVPM), melhor será. Isto significa que o colaborador estará "fazendo a coisa certa na primeira vez" e consequentemente menos $\mathrm{HH}$ estará sendo gasto no respectivo projeto. Pretende-se que este indicador seja menor do que dois, ou seja, que cada projeto seja modificado no máximo duas vezes sendo de responsabilidade do planejador.

\section{PERSPECTIVA DO APRENDIZADO E CRESCIMENTO}

Na última perspectiva do BSC, os objetivos definidos foram Motivar os funcionários, Fornecer feedback aos funcionários e Treinar funcionários. Estes três objetivos correspondem respectivamente às três categorias da perspectiva do aprendizado e crescimento: Motivação, empowerment e alinhamento; Capacidade dos sistemas de informação; e Capacidade dos funcionários.

Os objetivos Aumentar a satisfação dos empregados e Aumentar a satisfação dos prestadores de serviços foram retirados, pois entende-se que estes estão incorporados ao objetivo Motivar os funcionários. Os objetivos Implantar o sistema de lições aprendidas e Garantir histórico dos projetos foram suprimidos, pois entende-se que estão contemplados no objetivo Fornecer feedback aos funcionários. Já os objetivos Prover treinamentos, Garantir a participação em DSMS e Disseminar o conhecimento fazem parte do objetivo proposto Treinar funcionários.

Dessa forma, para o objetivo Motivar os funcionários foi definido o indicador Quantidade de Reuniões de Equipe de Projetos (QREP). Para o objetivo Treinar funcionários, dois indicadores foram propostos: Índice de Participação nos DSMS (IPDSMS) e o Índice de Disseminação do Conhecimento (IDC). Por fim, para o objetivo Fornecer feedback aos funcionários o indicador estabelecido foi o Índice de Histórico de Projetos (IHP).

Quanto ao QREP, as reuniões tem o intuito de apresentar mensalmente os indicadores de desempenho à equipe, motivando-os com o propósito de alinhar a equipe com os objetivos e metas da mesma. A meta é a realização de no mínimo uma reunião com a equipe de projetos mensalmente. $O$ coordenador da equipe será o responsável pela reunião e pela manutenção do indicador.

Uma vez o IPDSMS é mensurado pela gerência de segurança caberá ao coordenador da equipe de projetos solicitar e analisar estes dados. Deseja-se $90 \%$ de participação da equipe nos DSMS ao mês. Este valor é o mesmo da meta anterior, considerado bom e realizável pela equipe.

O IDC foi definido com o intuito de prover treinamentos aos colaboradores, pois como visto na entrevista com o coordenador a empresa não poderá fornecer treinamentos aos empregados contratados por regimento de contrato. Assim, para que estes ocorram, propõe-se que cada colaborador estude um assunto e repasse aos seus colegas através de workshops bimestrais de cada disciplina. Portanto, o IDC será calculado através da Equação (7):

$$
I D C=\sum \text { workshops }
$$


onde: $\sum$ workshops é a quantidade de workshops realizados por disciplina. o coordenador da equipe é o responsável pela elaboração do cronograma bimestral e registro deste indicador que possui meta de no mínimo um workshop por disciplina a cada dois meses.

Para calcular o IHP foi necessário rever o documento de histórico de projetos, pois este se encontrava desatualizado. Assim, o IHP será mensurado através da Equação (8):

$$
\text { IHP }=\frac{\left(n^{\circ} \text { proj.HP }\right)}{\left(n^{\circ} \text { tot.proj }\right)} \times 100 \%
$$

Onde: $\mathrm{n}$ o proj.HP representa o número de projetos com histórico preenchido e o no tot.proj o número total de projetos concluídos. O preenchimento do histórico de projetos tem o intuito de fornecer feedback em tempo hábil a todos os envolvidos no mesmo. Esse documento estará disponível na sua respectiva pasta que se encontra na rede de computadores. Propõe-se ainda a inclusão de uma coluna de lições aprendidas para que o conhecimento adquirido da experiência não seja perdido. Além disso, este documento será anexado a tramitação do projeto. O planejador é o responsável por este indicador que possui meta o mínimo de $60 \%$ dos históricos de projetos preenchidos em no máximo dois meses. Da mesma maneira do IPDSMS, este valor é o mesmo da meta anterior, considerado bom e realizável pela equipe.

Apesar de todas as considerações propostas de nada adiantará se a equipe do setor de projetos não entender o objetivo do BSC. Para que se obtenha sucesso, deverão ser realizadas reuniões mensais ou quinzenais com o intuito de informar a força de trabalho os conceitos relevantes desta metodologia, além de fornecer feedback quanto aos resultados obtidos com a alimentação dos indicadores. Outro fator importante para que o BSC não entre em desuso novamente, é que os responsáveis de cada indicador tenham o compromisso de verificar se as metas estão sendo atingidas e os indicadores alimentados.

\section{CONCLUSÕES}

Com a realização deste trabalho pode-se concluir que no setor de projetos da empresa do setor de petróleo havia um BSC que apresentava problemas, tais como, visão muito extensa e abrangente, falta de definição de responsáveis por cada indicador de desempenho, a definição de muitos objetivos sem que todos tivessem indicadores correspondentes, desequilíbrio entre os indicadores que permeavam as perspectivas do BSC, definições de objetivos associando-os aos indicadores, falta de indicador para a perspectiva do cliente e o excesso de indicadores, ressalta-se neste caso até mesmo a elaboração do índice de atualização dos indicadores que tinha o intuito monitorar os outros indicadores. Em decorrência destes problemas a equipe não conseguiu alcançar a nenhum dos objetivos inicialmente propostos.

Percebeu-se que quando um setor utiliza uma visão extensa, ou seja, tenta alcançar vários objetivos de uma só vez ele perde o foco e a estratégia fica perdida no tempo. Assim sendo, para que se tenha o alcance efetivo de uma estratégia esta deve ser bem específica e sempre reavaliada. 
A falta de definição de responsáveis por cada indicador impossibilitou que estes fossem realmente controlados, uma vez que não há cobrança e nem punições. Apesar disso, o coordenador ressaltou várias vezes a necessidade de utilização de uma ferramenta que mostrasse o desempenho de sua equipe e desta forma ele não soube delegar funções e nem incentivar a equipe na utilização do BSC.

Muitos objetivos foram definidos sem que todos recebessem um indicador, isto levou a objetivos importantes como, por exemplo, o ISC a não ser mensurado, e indo contra totalmente o que diz as relações de causa e efeito. Além disso, o número elevado de objetivos deixou o BSC pouco prático ainda mais por se tratar de uma equipe. Para que um BSC seja efetivo, devem-se propor objetivos adaptados à realidade do ambiente e que realmente seja entendido e interessante a todos.

O fato de se ter elaborado muitos indicadores associados às perspectivas internas, que mesmo fáceis e possíveis de serem realizados, desestimulou o uso dos mesmos. Portanto, ao se elaborar um BSC deve-se considerar o equilíbrio entre as perspectivas para que o resultado almejado seja atingido.

$\mathrm{Na}$ elaboração de um BSC deve-se primeiramente pensar nos objetivos estratégicos e suas relações de causa e efeito que contarão a estratégia a ser seguida pela organização ou setor. Dessa forma os indicadores são uma consequência dos objetivos propostos e não o contrário.

Pode se ressaltar que o excesso de objetivos ocasionou um elevado número de indicadores o que levou o BSC a ficar ainda mais confuso e pouco operacional. Outra questão diz respeito à repetição de informações por vários indicadores sem necessidade, isto gera custos e uso indevido do tempo já escasso no setor de projetos. Portanto, bons indicadores devem ser acessíveis e fáceis de serem mensurados.

Deste modo foi elaborado um novo BSC com sete objetivos e doze indicadores com base em proposta de uma nova estratégia. Percebeu-se que a melhor estratégia para o setor seria focado no aumento da produtividade e redução dos custos operacionais. Ao elaborar o BSC foi necessário rever e propor novos indicadores. Isto porque existia indicador adequado, mas que por falta de acompanhamento não estava sendo utilizado como, por exemplo, o ICC.

Além disso, cabe ressaltar que ao alimentar o ICC foi constatado um problema de orçamentação. Para resolver este problema necessitou-se verificar a forma pela qual o orçamento estava sendo realizado. Conclui-se, portanto, que uma das causas era a má técnica utilizada para a execução desta atividade. Por conseguinte, um direcionador de custo teve de ser determinado, pois se acredita que este dará maior confiabilidade e veracidade ao planejamento do orçamento de cada projeto. Isto mostra que a não utilização de indicadores adequados impossibilita que outros problemas venham a ser identificados e corrigidos a tempo.

Quanto à perspectiva de clientes não há uma cultura de se mensurar a satisfação dos mesmos. Isto devido ao temor de receber várias reclamações e não conseguir respondê-las a contento. Assim, foi proposto um indicador que levasse em conta questões internas e evitaram-se questões subjetivas, pois estas 
não contribuiriam em nada no crescimento do setor. Isto mostra a importância de se considerar questões internas do setor.

Quanto às perspectivas dos processos internos e aprendizado e crescimento mesmo trabalhando-se com o intuito de obter equilíbrio entre as quatro perspectivas estas receberam maior número de objetivos e indicadores. No entanto, isto não poderia ser diferente visto que se trata de um setor de projetos que não possui funções financeiras e clientes "tradicionais".

Para finalizar é importante ressaltar que neste trabalho foi abordado além da elaboração do BSC as fases de implementação e operacionalização de alguns indicadores. O QNCPR demonstrou a implementação de um indicador e o ICC ilustrou a operacionalização de outro. Estas experiências são interessantes para o meio acadêmico, pois na revisão bibliográfica realizada se encontrou pouca menção a respeito desse tipo de experiência. Os trabalhos encontrados deram ênfase a teoria da implementação da metodologia, dando pouco enfoque à parte prática desta.

Assim, constata-se a necessidade da conscientização de que o BSC não tem um fim nele mesmo, que deverão ser tomadas providencias para concluir a sua implantação e que ele é um processo que deve ser constantemente avaliado e realimentado. Prova disso é que o QNCPR proposto por esse modelo está sendo utilizado. Este sofreu barreiras iniciais, mas foram sanadas por meio do seu responsável. Pode-se com isso englobar toda a gerência em prol de um mesmo objetivo.

Portanto espera-se que o novo BSC possa fornecer ao coordenador informações úteis quanto ao desempenho de sua equipe. Ao reduzir o número de projetos pendentes e o número de não conformidades este estará reduzindo os custos. Ao reduzir o tempo de elaboração dos projetos este aumentará a satisfação dos seus clientes.

A principal limitação deste trabalho está intrínseca aos estudos em um único caso que não permitem que se façam generalizações, nem mesmo com empresas do mesmo setor ou porte. No intuito de minimizar este problema e ampliar o conhecimento a este respeito propõe-se como sugestão de trabalhos futuros, à volta a empresa para verificar se o modelo proposto foi utilizado em suas plenas potencialidades e, assim, reavaliá-lo em virtude do novo ambiente empresarial, implicando melhorias contínuas. 


\title{
Analysis of critical factors for implementing Balanced Scorecard: solutions for the project sector of a petroleum company
}

\begin{abstract}
This article had the objective of analyzing the difficulties faced by the Project Team, of an oil company with operations in Espírito Santo, regarding the implementation of the Balanced Scorecard (BSC) and propose solutions. For that, a case study was carried out, mainly using semi-structured interviews and documentary analysis. There were several problems in the existing BSC, such as very extensive and comprehensive vision, lack of definition of responsible for each performance indicator, definition of many objectives without all having corresponding indicators, imbalance between the indicators that permeated the perspectives of BSC, etc. As a result of these problems the team could not reach any of the objectives initially proposed. In order to correct and minimize the previous problems, a new strategy has been elaborated given the need of the sector that has a great demand for projects and can not produce it with the same speed as they arrive. The proposed BSC presents seven strategic objectives and twelve indicators with the purpose of increasing the productivity as well as the quality of the works carried out by the team. In addition, it is expected that this new version of BSC will be more effective and that it will allow its effective implementation and operationalization.
\end{abstract}

Strategy. Balanced Scorecard (BSC). Perspectives. Goals. Indicators. 


\section{REFERÊNCIAS}

AL-DWEIKAT, M. F. S.; NOUR, M. I. Balanced Scorecard critical success factors of Jordanian Commercial Banks and its effect on financial performance. Accounting and Financial Research, 7, 3, 146-153, 2018. crossref

ALOLAH, T.; STEWART, R. A.; PANUWATWANICH, K.; MOHAMED, S. Determining the causal relationships among Balanced Scorecard perspectives on school safety performance: Case of Saudi Arabia. Accident Analysis and Prevention, 68, 57-74, 2014. crossref

BERTUCCI, J. L. de O.; HIRSCHEIMER, E. Sistemas de avaliação de performance em empresas do setor de serviços: o desafio de alinhar estratégias e processos. In: ENCONTRO ANUAL DA ANPAD, 2005, Brasília. Anais Contabilidade Gerencial e Controladoria. Brasília, p.1-16. Disponível em:

<revistas.pucsp.br/index.php/rad/article/download/669/466>. Acesso em: 25 mai. 2012.

CHENG, M. M.; HUMPHREYS, K. A. Managing strategic uncertainty: the diversity and use of performance measures in the Balanced Scorecard. Managerial Auditing Journal, 31, 512-534, 2016. crossref

CUNHA, M. R.; KRATZ, L. Fatores Críticos de Sucesso no Processo de Implementação do Balanced Scorecard: um estudo de caso nas Instituições Federais de Ensino Superior. Revista de Ciências da Administração, 18, 46, 96108,2016 . crossref

HU, B.; LEOPOLD-WILDBURGER, U.; STROHHECKER, J. Strategy map concepts in a Balanced Scorecard cockpit improve performance. European Journal of Operational Research, 258,664-676, 2017. crossref

JUN, L. C. C.; NISHIMOTO, H.; ABREU, N. C.; SIQUEIRA, V.; TOLEDO, L. A. Hunger Marketing um novo caminho para as empresas de smartphones, ou não? O caso Xiaomi. Revista Gestão Industial, 12, 3, 119-144, 2016.

KAPLAN, R.S., NORTON, D.P. The Balanced Scorecard-measures that drive performance. Harvard Business Review, 70 (1), 71-79, 1992.

KAPLAN, R. S.; NORTON, D. P. A Estratégia em Ação: Balanced Scorecard. Rio de Janeiro: Elsevier, 1997. 
KAPLAN, R. S.; NORTON, D. P. Organização orientada para a estratégia: Como as empresas que adotam o Balanced Scorecard prosperam no novo ambiente de negócios. Rio de Janeiro: Elsevier, 2000.

RAJESH, R.; PUGAZHENDHI, S.; GANESH, K.; DUCQ, Y.; KOH, S. C. L. Generic Balanced Scorecard framework for third party logistics service provider. Int. J. Production Economics, 140, 269-282, 2012. crossref

MERCER, A. C.; WILDAUER, E. W. 29 fatores críticos de sucesso na implementação do Balanced Scorecard em organizações. Ciências Sociais Aplicadas em Revista, 15, 28, 41-64, 2015.

MENDES, P.; SANTOS, A. C.; PERNA, F.; TEIXEIRA, M. R. The Balanced Scorecard as an integrated model applied to the Portuguese public service: a case study in the waste sector. Journal of Cleaner Production, 24, 20-29, 2012. crossref

MOREIRA, F. A. L.; PESSOA, M. N. M.; CABRAL, A. C. A.; SANTOS, S. M.; ROLDAN, V.P. S. Fatores críticos na implantação do Balanced Scorecard - BSC. Revista Eletrônica Estratégia e Negócios, 5, 3, 57-89, 2012.

SAAD, R. I.; DARAGHMA, Z. M. A. Using of the Balanced Scorecard for performance evaluation: empirical evidence from the listed Corporations in the Palestine Exchange (PEX). International Journal of Bussiness and Management, $11,3,215-222,2016$. crossref

GUERRA, J. B. S. O. de A.; GARCIA, J.; LIMA, M. de A.; BARBOSA, S. B.; HEERDT, M. L.; BERCHIN, I. I. A proposal of a Balanced Scorecard for an environmental education program at universities. Journal of Cleaner Production, 172, 16741690,2018 . crossref

UPADHYAY, A. Y. A. Balanced Scorecard - fostering learning organazitions towards achieving strategic results: a case study of an oil PSU in India. Development and Learning in Organizations, 26, 4, 13-16, 2012.

VIEIRA, G. B. B.; MÜLLER, C. J.; KLIEMANN NETO, F. J. O posicionamento competitivo de uma empresa atuante no comércio varejista de artigos esportivos pela ótica de seus clientes. Revista Gestão Industrial, 9, 3, 681-699, 2013. crossref 
Recebido: 07 mai. 2018

Aprovado: 14 fev. 2019

DOI: $10.3895 /$ gi.v15n1.8272

Como cital:

SOUZA, N. B. P.; TOSTA, M. C. R. Análise dos fatores críticos de implementação do Balanced Scorecard: soluções para o setor de projetos de uma empresa petrolifera. R. Gest. Industr., Ponta Grossa, v. 15, n. 1, p. 01-25, jan./mar. 2019. Disponível em: $\leq$ https://periodicos.utfpr.edu.br/rgi . Acesso em: XXX.

Correspondência:

Noéle Bissoli Perini de Souza

Rodovia BR 101, km 65, 2121, Santo Antônio, São Mateus, Espírito Santo, Brasil.

Direito autoral: Este artigo está licenciado sob os termos da Licença Creative Commons-Atribuição 4.0

Internacional.

(c) (1) 